J. Lake Sci.(湖泊科学), 2019, 31(3): 677-688

DOI 10. 18307/2019. 0307

(c) 2019 by Journal of Lake Sciences

\title{
大型表面流人工湿地长期运行下底泥污染特性及氧化层甄别”
}

\author{
张 雪 $^{1}$, 姜翠玲 ${ }^{1}$, 朱立琴 ${ }^{1 * *}$, 杜观超 ${ }^{2}$, 高 㝵 $^{2}$, 陈红卫 ${ }^{3}$, 李峰东 ${ }^{2}$, 张海阔 ${ }^{1}$, 秦 文凯 $^{1}$, 朱伊 \\ 梦 $^{1}$, 李一平 ${ }^{1}$ \\ (1: 河海大学,南京 210098) \\ (2:盐城市盐龙湖饮用水源管理处,盐城 224014) \\ ( 3 :盐城市节约用水办公室,盐城 224001)
}

\begin{abstract}
摘 要: 研究湿地底泥污染特性及水一土界面边界层性质是明确大型人工湿地长期运行下底泥内源污染问题的关键. 本 文以典型人工湿地为例, 通过综合布点垂向分层监测湿地底泥理化性质, 明确底泥污染特性, 分析水一土界面边界氧化层 现象、性质及形成机理, 探讨其性质成因. 结果表明: 与湖泊类似,长期运行人工湿地底泥也会产生氧化层,垂向由上到下 分为氧化层、污染层、过渡层和健康层; 运行 6 年的湿地底泥可形成厚约 $1 \mathrm{~cm}$ 、无明显臭味、棕黄色可塑状的氧化层; 与污 染层相比, 氧化层色味变淡、流动性减弱, 含水率、 $\mathrm{d}(0.9)$ 、亚铁、总有机碳和总氮含量分别降低 $7.20 \% 、 54.04 \% 、 54.59 \%$ 、 $17.89 \%$ 和 $7.00 \%$, 氧化还原电位和总磷含量分别升高 $150.41 \%$ 和 $18.17 \%$; 氧化层是由氧化、沉降协同作用下形成的底泥 表层氧化态微环境, 其中上覆水溶解氧水平越高越有利于提高氧化层致密程度, 降低氧化层有机质、总氮含量, 上覆水悬 浮物浓度越高、水深越深越有利于增加氧化层厚度.
\end{abstract}

关键词: 人工湿地;底泥污染;氧化层;形成机理;盐龙湖

\section{The characteristics of sediment pollution and the identification of oxidation layer under long-term operation of large-scale surface flow constructed wetlands}

ZHANG Xue $^{1}$, JIANG Cuiling ${ }^{1}$, ZHU Liqin ${ }^{1 * *}$, DU Guanchao ${ }^{2}$, GAO Xu ${ }^{2}$, CHEN Hongwei $^{3}$, LI Fengdong ${ }^{2}$, ZHANG Haikuo $^{1}$, QIN Wenkai ${ }^{1}$, ZHU Yimeng ${ }^{1}$ \& LI Yiping ${ }^{1}$

(1: Hohai University, Nanjing 210098, P.R.China)

(2: Yanlong Lake Drinking Water Sources Administrative Office, Yancheng 224014, P.R. China)

(3: Water Conservation Office, Yancheng 224001, P.R. China)

Abstract : The study on the characteristics of sediment pollution and the boundary layer of water-soil interface is the key to identify the problem of sediment pollution under the long-term operation of large constructed wetlands. This paper takes a typical surface flow constructed wetland as an example, through comprehensive vertical layered monitoring of the physicochemical properties of the wetland sediment, to clarify the pollution characteristics of the sediment and analyzed the phenomenon, nature and formation mechanism of the boundary oxidation layer of the water-soil interface. The results show that, similar to lakes, the sediment of constructed wetland in long-term operation also generates oxidation layer, which is divided into oxidation layer, pollution layer, transition layer and health layer from top to bottom. After 6 years of operation, the wetland sediment can form an oxidation layer, which is about 1 $\mathrm{cm}$ thick, brown-yellow, malleable, with no obvious odor. Compared with the pollution layer, the color and smell of the oxidation layer are weakened, and its fluidity is weakened. Meanwhile, the water content, $\mathrm{d}(0.9)$, diatomic iron, total organic carbon and total nitrogen are decreased by $7.20 \%, 54.04 \%, 54.59 \%, 17.89 \%$ and $7.00 \%$. Eh and total phosphorus are increased by $150.41 \%$ and $18.17 \%$, respectively. Oxidation layer is a micro-environment of surface oxidation state formed under the synergistic

* 国家自然科学基金项目 (51879082,51609060)、江苏省自然科学基金青年基金项目 (SBK2015042806)和中央高校 基本科研业务费专项 (2018B48214,2018B48114,2017B14614) 联合资助. 2018-08-04 收稿; 2018-11-15 收修改 稿. 张雪 (1993 ), 女, 硕士研究生;E-mail: zx227_hhu@163.com.

** 通信作者;E-mail: lqzhu@ hhu.edu.cn. 
action of oxidation and settlement. The higher the dissolved oxygen level of overlying water is, the more favorable it is to increase the density of the oxidation layer and reduce the organic matter and total nitrogen content of the oxidation layer. In addition, the higher the concentration of overlying water suspended substance and the deeper the water depth, the more favorable it is to increase the thickness of the oxidation layer.

Keywords: Constructed surface flow wetland; pollution of sediment; oxidation layer; formation mechanism; Yanlong Lake

表面流人工湿地是目前常用的水质净化措施 ${ }^{[1]}$. 但长期运行人工湿地会呈现 “饱和状态”, 对污染物的 吸附、截留和转化作用减弱, 净化功能逐渐衰退甚至出现底泥内源污染问题 ${ }^{[2]}$. 研究湿地底泥污染特性及 水一土界面边界层性质是研究水一土界面污染物迁移转化规律、湿地底泥内源污染问题的关键. 以往关于湖 泊底泥的研究发现, 上覆水环境健康的底泥表层会形成氧化层, 底泥垂向尺度由上到下可分为氧化层、污染 层、污染过渡层、健康层 ${ }^{[3]}$. 氧化层即为水一土界面边界层, 其理化性质与其他层均有不同. 姜霞等定性研究 了氧化层理化性质及其影响因素, 结果表明氧化层与污染层分界明显, 与污染层相比臭味减弱、颜色变浅、 氧化还原电位 $(\mathrm{Eh})$ 升高 $^{[3-4]}$, 氧化层性质受上覆水溶解氧水平、植物泌氧水平、人为疏浚等多种因素的影 响 ${ }^{[4-6]}$. 李一平等 ${ }^{[7]}$ 指出, 氧化层的形成易产生铁、锰等氧化物, 阻止下层污染物的释放及上覆水溶解氧向底 泥深层扩散. 冼萍等 ${ }^{[8]}$ 利用底泥微孔曝气以形成氧化层, 从而减少底泥污染内源释放. 因此, 与河湖类似, 若 长期运行的表面流人工湿地底泥也形成氧化层, 该层的形成可能会对湿地水一土界面溶解氧及底泥污染物 的迁移扩散规律产生重要影响 ${ }^{[9]}$. 因此, 研究湿地长期运行下底泥是否形成氧化层、氧化层性质及形成机理 是研究湿地水一土界面污染物迁移转化规律、解决湿地底泥内源污染问题的前提.

综上所述, 研究人工湿地底泥污染特性及氧化层的判定、性质及形成机理是解决湿地内源问题的理论 前提. 目前关于人工湿地底泥污染特性的研究鲜有报道, 尤其还未对大型人工湿地长期运行后底泥污染特 性及水一土界面边界层性质进行系统研究. 因此, 本文选取国内最大的水源地人工湿地工程盐龙湖工程挺水 植物生态净化区运行 6 年后的原状底泥作为研究对象, 首先布点分层监测底泥理化性质, 明确底泥污染垂 向变化特性, 判断底泥是否形成氧化层并指出氧化层的判定指标, 其次研究氧化层与其他深度底泥理化性 质差异特征、氧化层理化性质空间分布特征, 最后与湖泊和其他湿地作对比分析, 深人探讨长期运行人工湿 地底泥污染特性、氧化层性质与形成机理及对湿地水一土界面物质迁移转化可能产生的影响, 以期为解决大 型表面流人工湿地长期运行后产生的底泥内源污染问题奠定理论基础.

\section{1 材料与方法}

\section{1 研究区概况}

盐龙湖净化工程位于江苏盐城市盐都区龙冈镇境内, 总占地面积 222.8 万 $\mathrm{m}^{2}$, 以微污染河水为净化水 源, 是国内外目前建成规模最大、兼具常规供水与应急备用功能的生态水利工程. 该工程于 2012 年 6 月正 式通水运行, 截至 2018 年 7 月已成功运行长达 6 年之久. 盐龙湖挺水植物生态湿地净化区是该净化工程核 心单元之一, 面积 41.3 万 $\mathrm{m}^{2}$, 分 $A 、 B 、 C 3$ 个区梯级控制, 常水位条件下, 湿地水深分别为 $0.3 、 0.4$ 和 $0.5 \mathrm{~m}$, 每一梯级有 3 个并联净化单元, 平均水力负荷为 $0.73 \mathrm{~m} / \mathrm{d}$. 该区采用羽状布水, 进水由配水总渠通过涵闸、 布水渠均匀进人各净化单元, 净化后的水体通过湿地两侧集水干渠收集, 是国内比较典型的长期运行的大 型表面流人工湿地. 湿地表面主要优势物种为芦苇和艾草, 湿地植物每年春天和冬天各收割一次地上部分, 湿地植物密度分别为 20 40 和 100 140 株/ $\mathrm{m}^{2}$, 植物长势情况如图 1 所示. 该湿地累积运行 6 年, 期间未进 行底泥清淤, 对污染物的去除效率不断减弱, 底泥污染物累积水平较高, 呈现 “饱和” 状态, 偶尔还会出现底 泥内源污染问题. 该湿地多年平均进、出水水质见表 1 .

\section{2 样品采集与分析}

2017 年 12 月在无明显降雨发生时段并且停止进水 20 天后在湿地中根据不同水深 ( A 、 B 和 C 区分别为 $0.3 、 0.4$ 和 $0.5 \mathrm{~m}$ ) 、同一净化单元不同位置 (进水口、中间和出水口) 两个控制变量选取 9 个具有代表性的底 泥采样点 $\mathrm{A}$ 区进水口、 $\mathrm{A}$ 区中间、 $\mathrm{A}$ 区出水口、 $\mathrm{B}$ 区进水口、 $\mathrm{B}$ 区中间、 $\mathrm{B}$ 区出水口、 $\mathrm{C}$ 区进水口、 $\mathrm{C}$ 区中间、 $\mathrm{C}$ 区出水口), 采样点分布如图 2 中五角星所示. 在各个采样点实地勘察底泥剖面垂向分层结构, 记录底泥颜 
表 1 盐龙湖湿地多年平均进、出水水质 *

Tab.1 Influent and effluent water quality of Yanlong Lake Wetland

\begin{tabular}{cccc}
\hline 项目 & 进水水质 $/(\mathrm{mg} / \mathrm{L})$ & 出水水质 $/(\mathrm{mg} / \mathrm{L})$ & 去除率/提升率 \\
\hline 总氮 $(\mathrm{TN})$ & 1.47 & 1.14 & $22.39 \%$ \\
总磷 $(\mathrm{TP})$ & 0.197 & 0.175 & $10.98 \%$ \\
高锰酸盐指数 $\left(\mathrm{COD}_{\mathrm{Mn}}\right)$ & 6.14 & 6.04 & $1.68 \%$ \\
悬浮物 $(\mathrm{SS})$ & 20.71 & 13.25 & $36.03 \%$ \\
溶解氧 $(\mathrm{DO})$ & 6.99 & 4.49 & $-35.79 \%$ \\
\hline
\end{tabular}

* 除 DO 为提升率外,其他指标均为去除率.

色、气味、状态、厚度等指标并在各个采样点垂向尺度上 分别采 $0 \sim 1 、 1 \sim 2 、 2 \sim 3 、 3 \sim 4 、 4 \sim 10 、 10 \sim 20 、 20 \sim 30 \mathrm{~cm}$ 的 泥样装人密封袋, 尽快运回实验室进行化验分析, 分别 检测各层底泥含水率、粒径分布 ( 细端粒径 $\mathrm{d}(0.1)$ 、中值 粒径 $\mathrm{d}(0.5)$ 、粗端粒径 $\mathrm{d}(0.9)$ )、总有机碳 (TOC) 含量、 总氮 (TN) 含量、总磷 (TP) 含量, 检测方法如表 2 所示. 2018 年 8 月在湿地正常运行情况下采原状底泥进行连 续 28 天柱状带水培养 (室内恒温 $25^{\circ} \mathrm{C}$ ), 期间每隔 3 天 检测底泥 $0 \sim 1$ 与 $1 \sim 4 \mathrm{~cm}$ 之间 $\mathrm{Eh}$ 及亚铁含量, 检测方法 如表 2 所示.

利用 Excel 软件绘制以上理化性质垂向分布曲线, 并采用 9 个点数据标准误差绘制误差线. 利用 SPSS 软件对相邻层级之间数据分别进行配对 $t$ 检验得出 $P$ 值. 利用 Excel 软件绘制 $0 \sim 1 \mathrm{~cm}$ 底泥理化性质空间分布图. 利用 Excel 软件绘制各层理化性质均值条形对 比图,并利用 9 个点数据标准误差绘制误差线.

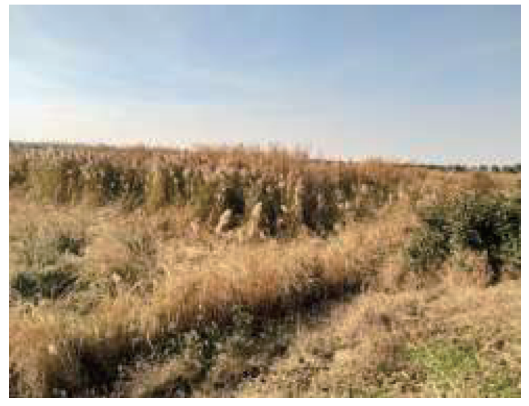

图 1 盐龙湖湿地植物生长状况

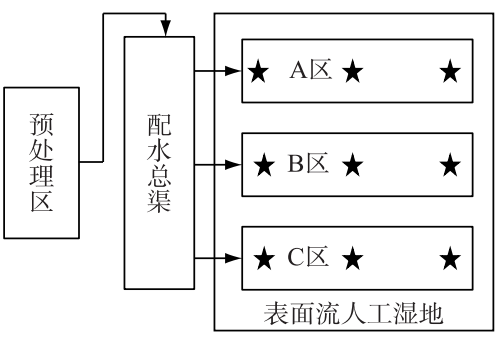

图 2 盐龙湖湿地采样点分布

Fig. 2 Location of sampling sites in Yanlong Lake Wetland

Fig.1 Plant growth of Yanlong Lake Wetland

Tab.2 Detection methods of sediment samples

\begin{tabular}{cc}
\hline 检测项目 & 检测方法 \\
\hline 氧化还原电位 & 电极法 \\
亚铁 & 硫酸铝浸提一邻菲罗啉显色法 \\
含水率 & 重量法 \\
粒径分布 & 马尔文 3000 激光粒径分析仪法 \\
总有机碳含量 & 重铬酸钾氧化外加热法 \\
总氮含量 & 半微量开氏法 \\
总磷含量 & $\mathrm{NaOH}$ 熔融一钼锑抗比色法 \\
\hline
\end{tabular}

表 2 底泥样口检测方法 

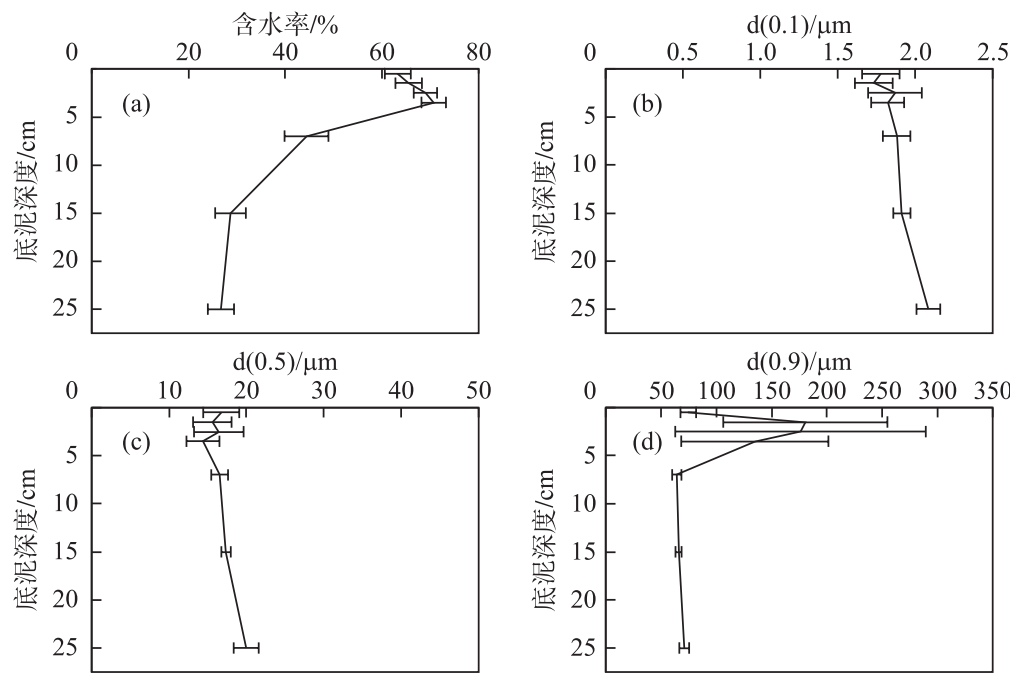

图 3 盐龙湖湿地底泥物理性质垂向分布

Fig.3 Vertical distributions of physical property of Yanlong Lake Wetland sediments
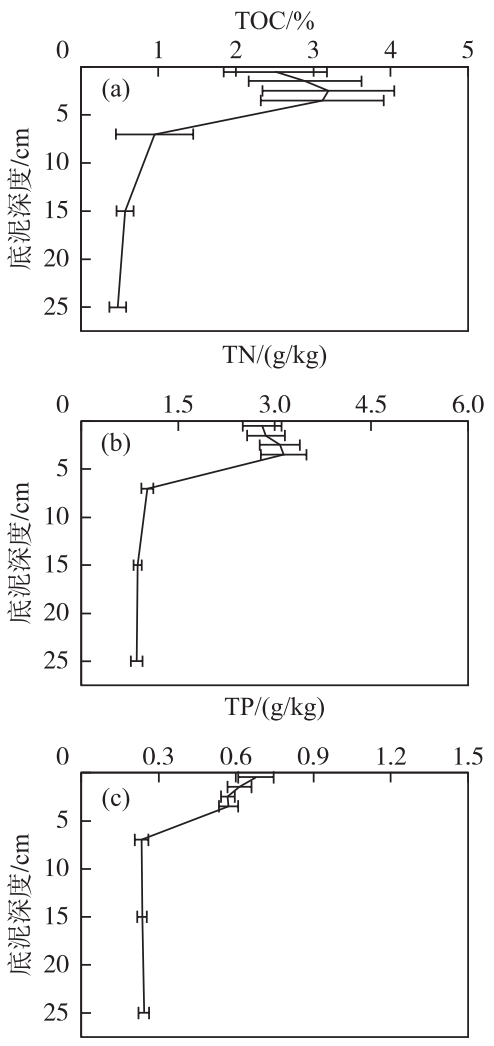

图 4 盐龙湖湿地底泥化学性质垂向分布

Fig.4 Vertical distributions of chemical property of Yanlong Lake Wetland sediments
2.1 .2 底泥化学性质垂向分布特征由图 4 可知,湿地底泥 TOC、TN、TP 含量均存在明显分层结构. $10 \mathrm{~cm}$ 以上, TOC、 $\mathrm{TN}$ 含量均呈现先升后降的趋势, TP 含量呈现先降低后略升 高的趋势. TOC 含量在 2 3 cm 之间达到峰值( $3.195 \%), 0 \sim$ 1 和 $4 \sim 10 \mathrm{~cm}$ 相比峰值分别降低 $21.44 \%$ 和 70.23\%. TN 含量 在 3 4 cm 之间达到峰值( $3.139 \mathrm{~g} / \mathrm{kg}$ ) , $0 \sim 1$ 和 $4 \sim 10 \mathrm{~cm}$ 相 比峰值分别降低 $10.61 \%$ 和 $67.35 \%$. TP 含量在表层 $0 \sim 1 \mathrm{~cm}$ 之间达到峰值 $(0.677 \mathrm{~g} / \mathrm{kg}), 1 \sim 4 、 4 \sim 10$ 和 $10 \mathrm{~cm}$ 以下相比 峰值依次降低 $13.59 \%$ 、65.44\% 和 $64.70 \%$. $10 \mathrm{~cm}$ 以下, TOC、TN、TP 含量均稳定在较低水平, 无明显变化.

\section{2 湿地氧化层的判定及其空间分布特征}

2.2 .1 氧化层判定指标 氧化层与其他各层存在明显理化性 质差异, 判定底泥氧化层是否形成应结合底泥颜色、气味、 状态等现场勘查指标和 Eh、亚铁、含水率、粒径分布、TOC 含 量、TN 含量、TP 含量等室内检测结果分层对比分析, 若水土 界面边界层底泥与其相邻层在以上指标上存在较为明显的 差异, 则可判断为氧化层形成. 通过现场观察湿地底泥垂向 剖面结构并结合数据分析结果, 对比底泥各层颜色、气味、 状态及理化性质发现, $0 \sim 1 \mathrm{~cm}$ 为棕黄色、无明显恶臭气味、 较干燥且不易流动的水一土界面边界层, 与其下层存在明显 分层界面. 1 4 cm 颜色较深, 有明显恶臭气味, 多孔疏松易 流动, 含水率、 $\mathrm{d}(0.9)$ 、 TOC 和 TN 含量均达到峰值, 说明该 层有机质总氮污染累积程度最为明显. 所以, 根据 $0 \sim 1$ 与 $1 \sim 4 \mathrm{~cm}$ 之间颜色、气味、状态等感官指标及含水率等定量 指标的差异性可初步判定, 底泥 $0 \sim 1 \mathrm{~cm}$ 即为人工湿地多年 运行条件下产生的氧化层, $1 \sim 4 \mathrm{~cm}$ 为湿地底泥内源污染物 
的主要蓄积层即污染层, 氧化层和污染层现场勘查分层 界面对比结果如图 5 所示. 为验证上述判定氧化层形成 的判定结果, 对氧化层和污染层之间的理化性质进行显 著性差异检验 (配对 $t$ 检验), 如表 3 所示. 可以看出在 $85 \%$ 置信区间下, 氧化层与污染层含水率、 $\mathrm{d}(0.9)$ 、Eh、亚 铁、TOC 含量、TN 含量、TP 含量均有显著性差异, 因此, 上述判定具有统计学意义, 氧化层确实存在.

本文基于以上氧化层与污染层的显著性差异提出 盐龙湖人工湿地冬季底泥氧化层的判定指标及定量指 标的具体数值范围, 如表 4 所示, 以便在实际研究中为氧 化层的存在给出判定依据.

2.2.2 氧化层理化性质空间分布特征 由图 6 可知, 同一 湿地净化单元不同位置由进水口至出水口方向, 氧化层

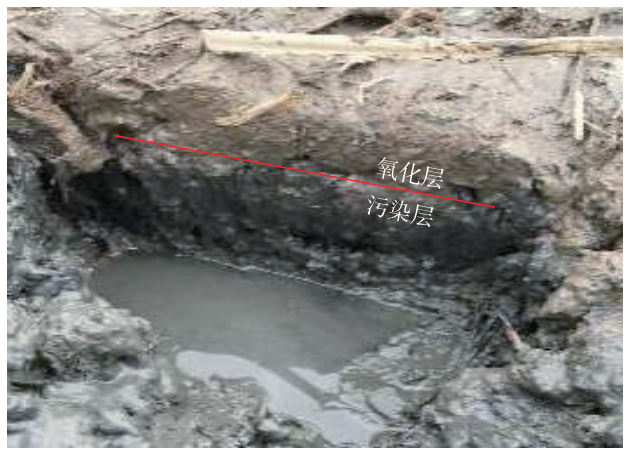

图 5 现场勘查氧化层与污染层垂向分层界面 Fig.5 Vertical stratified interface of oxidation and property of Yanlong Lake Wetland sediments 不断变薄, 氧化层出水口含水率均大于进水口, $\mathrm{d}(0.1)$ 与 $\mathrm{d}(0.5)$ 变化趋势相似,除运行水深 $0.4 \mathrm{~m}$ 外, 其他水深均为进水口氧化层 $\mathrm{d}(0.1)$ 和 $\mathrm{d}(0.5)$ 小于中间和出 水口. 除运行水深 $0.5 \mathrm{~m}$ 外, 其他水深均为进水口 $\mathrm{d}(0.9)$ 小于出水口. 由进水口至出水口方向, 氧化层 TOC 和 TN 含量变化趋势有明显相关性, 峰值均出现在中间或出水口位置, 除 $0.5 \mathrm{~m}$ 运行水深进水口和出水口 TOC 含量相当之外, 其他水深均为进水口小于出水口. 整体来看, 氧化层 TP 含量在中间达到峰值, 进水口 $\mathrm{TP}$ 含量略大于出水口. 湿地氧化层随运行水深的增加不断变厚, 除中间位置外, 其他位置均随水深的增加, 氧化层含水率不断降低, 除进水口位置, 其他位置氧化层粒径均随水深的增加呈下降趋势, 所以氧化层致密 程度变大. 整体来看, 随水深增加氧化层 TOC、TN 和 TP 含量均有下降趋势.

表 3 盐龙湖湿地底泥氧化层与污染层之间理化性质配对 $t$ 检验 $P$ 值

Tab.3 Physicochemical difference significance test of wetland sediments oxide layer and pollution layer

\begin{tabular}{cccccccccc}
\hline 指标 & 含水率 & $\mathrm{d}(0.1)$ & $\mathrm{d}(0.5)$ & $\mathrm{d}(0.9)$ & $\mathrm{Eh}$ & $\mathrm{Fe}^{2+}$ & $\mathrm{TOC}$ & $\mathrm{TN}$ & $\mathrm{TP}$ \\
\hline$t$ 检验 $P$ 值 & 0.003 & 0.903 & 0.330 & 0.119 & 0.001 & 0.000 & 0.037 & 0.129 & 0.001 \\
\hline
\end{tabular}

表 4 盐龙湖湿地底泥氧化层判定指标”

Tab.4 Identification indexs of oxide layer in Yanlong Lake Wetland sediments

\begin{tabular}{ccccc}
\hline 表征指标 & 指标 & 氧化层 & 污染层 & 氧化层与污染层差异描述 \\
\hline 物理指标 & 颜色 & 颜色较浅 & 颜色发黑 & 较污染层相比, 颜色明显变浅 \\
& 气味 & 无明显恶臭气味 & 有明显恶臭气味 & 较污染层相比,恶臭气味明显减弱 \\
& 状态 & 可塑状 & 流塑状 & 较污染层相比,流动性明显减弱 \\
& 含水率 & $48.73 \% \sim 75.33 \%$ & $57.74 \% \sim 79.64 \%$ & 较污染层相比,含水率降低 7.20\% \\
& $\mathrm{d}(0.1)$ & $1.36 \sim 2.42 \mu \mathrm{m}$ & $1.23 \sim 2.23 \mu \mathrm{m}$ & 氧化层粒径分布更细更均匀,无明显大颗粒 \\
& $\mathrm{d}(0.5)$ & $7.35 \sim 29.70 \mu \mathrm{m}$ & $6.48 \sim 25.66 \mu \mathrm{m}$ & \\
化学指标 & $\mathrm{d}(0.9)$ & $34.40 \sim 106.22 \mu \mathrm{m}$ & $43.25 \sim 418.24 \mu \mathrm{m}$ & \\
& $\mathrm{Eh}$ & $154 \sim 349 \mathrm{mV}$ & $74 \sim 111 \mathrm{mV}$ & 较污染层相比, Eh 升高约 $150.41 \%$ \\
& 亚铁 & $0.16 \sim 1.49 \mathrm{mg} / \mathrm{g}$ & $1.55 \sim 1.89 \mathrm{mg} / \mathrm{g}$ & 较污染层相比,亚铁含量升高约 $54.59 \%$ \\
& $\mathrm{TOC}$ & $0.19 \% \sim 6.67 \%$ & $0.69 \% \sim 7.34 \%$ & 较污染层相比, TOC 含量约降低 $17.89 \%$ \\
& $\mathrm{TN}$ & $1.44 \sim 4.52 \mathrm{~g} / \mathrm{kg}$ & $1.493 \sim 4.11 \mathrm{~g} / \mathrm{kg}$ & 较污染层相比, TN 含量约降低 7.00\% \\
& $\mathrm{TP}$ & $0.45 \sim 1.10 \mathrm{~g} / \mathrm{kg}$ & $0.48 \sim 0.74 \mathrm{~g} / \mathrm{kg}$ & 较污染层相比, TP 含量约升高 $18.17 \%$ \\
\hline
\end{tabular}

$* \mathrm{Eh} 、$ 亚铁为夏季室内培养监测数据.

\section{3 湿地底泥分层特征及各层对比}

氧化层是湿地中水一土界面产生的氧化态微环境, 有机质、总氮、亚铁含量有所下降; 污染层为污染物累 

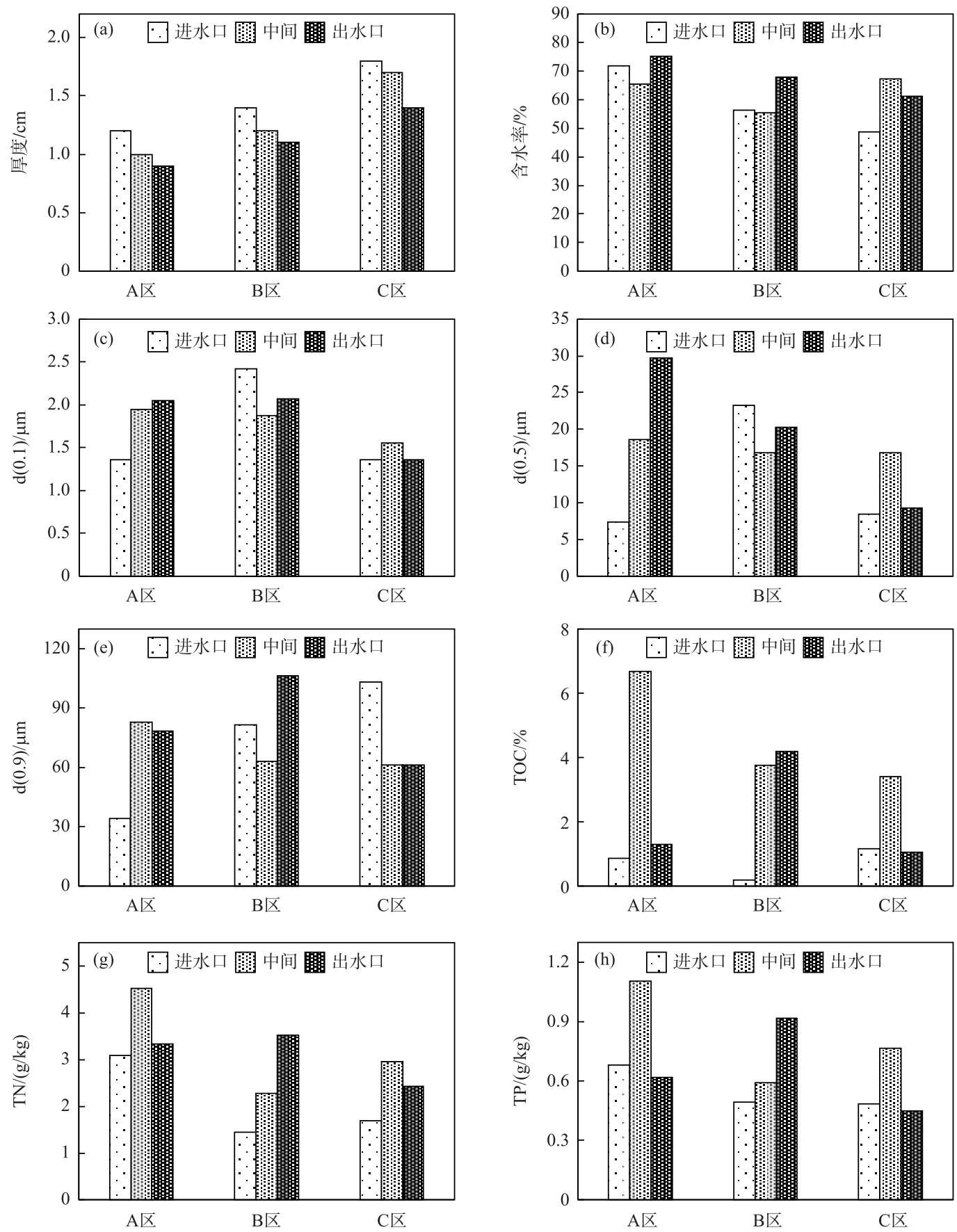

图 6 盐龙湖湿地底泥氧化层空间分布特征

Fig.6 Spatial distribution characteristics of oxide layers' physicochemical property in Yanlong Lake Wetland sediments

积主要区域,绝大多数污染物含量在该层达到峰值; 相对其他各层, $10 \mathrm{~cm}$ 以下的底泥中各污染物含量均较 低且相对稳定, 因此可以判断该层已完全脱离底泥污染区域, 与未受污染的原土层性质相一致, 把该层定义 
为健康层; 与其他层相比, $4 \sim 10 \mathrm{~cm}$ 之间的底泥中各污染物含量均有较大程度的下降, 因此可判断该层逐渐 远离污染区域, 为污染层向健康层的过渡, 把该层定义为过渡层. 盐龙湖大型表面流人工湿地长期运行下冬 季底泥分层特征见表 5. 现场勘查湿地底泥各分层颜色、状态对比结果见图 7.

表 5 盐龙湖湿地冬季底泥分层特征

Tab.5 Layered structure of Yanlong Lake Wetland sediments in winter

\begin{tabular}{|c|c|c|}
\hline 分层 & 尺度范围 & 特性描述 \\
\hline 氧化层 $(A)$ & $0 \sim 1 \mathrm{~cm}$ & $\begin{array}{l}\text { 棕黄色, 轻度土腥味, 无明显恶臭气味, 可塑状, 较 B 层相比, 含水率、TOC 含量、TN 偏 } \\
\text { 小, TP 偏大 }\end{array}$ \\
\hline 污染层 (B) & $1 \sim 4 \mathrm{~cm}$ & 黑色至棕黑色,有明显恶臭气味,呈半流态,含水率、粒径、TOC、TN 达到峰值 \\
\hline 过渡层 $(\mathrm{C})$ & $4 \sim 10 \mathrm{~cm}$ & 棕黑色, 有轻度恶臭气味, 呈半流塑态, 含水率、粒径、TOC、TN、TP 均有明显下降趋势 \\
\hline 健康层 $(\mathrm{D})$ & $10 \mathrm{~cm}$ 以下 & 棕黄色,无明显恶臭气味,呈塑态,含水率、粒径、TOC、TN、TP 含量均趋于稳定 \\
\hline
\end{tabular}

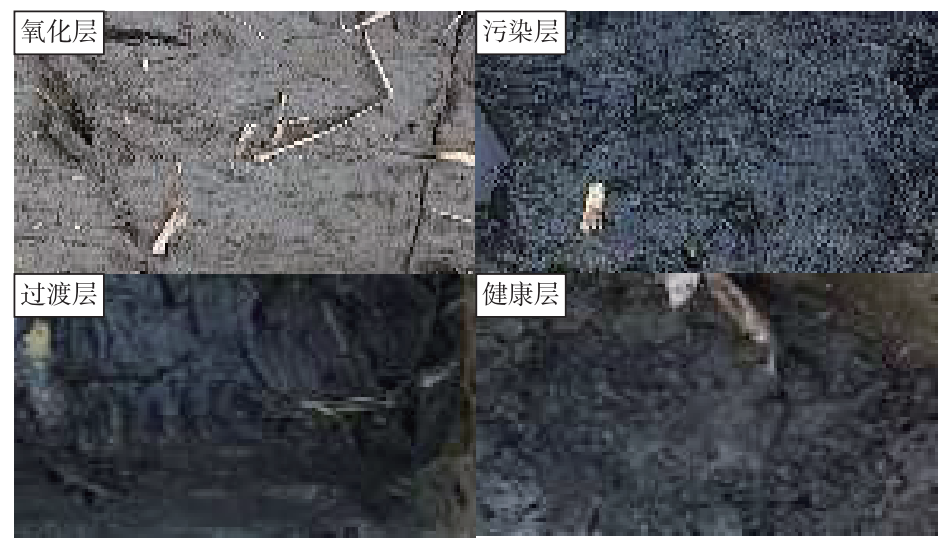

图 7 盐龙湖湿地底泥分层现场勘查结果

Fig.7 Stratification of Yanlong Lake Wetland sediments

为验证上述湿地底泥分层判定结果, 除对氧化层与污染层外, 对污染层、过渡层、健康层各相邻层之间 的理化性质也进行了差异显著性检验 (配对 $t$ 检验). 从表 6 可以看出, 在 $85 \%$ 置信区间下, 污染层与过渡层 含水率、 $\mathrm{d}(0.9)$ 、TOC 含量、TN 含量、TP 含量均有显著性差异; 在 70\% 置信区间下, 过渡层与健康层含水率、 $\mathrm{d}(0.1) 、 \mathrm{~d}(0.5) 、 \mathrm{TN}$ 含量均有显著性差异. 因此,上述分层判定结果较为合理,具有统计学意义.

表 6 盐龙湖湿地底泥污染层、过渡层、健康层相邻层理化性质配对 $t$ 检验 $P$ 值

Tab.6 Physicochemical difference significance test of each layer in Yanlong Lake Wetland sediments

\begin{tabular}{cccccccc}
\hline 项目 & 含水率 & $\mathrm{d}(0.1)$ & $\mathrm{d}(0.5)$ & $\mathrm{d}(0.9)$ & $\mathrm{TOC}$ 含量 & $\mathrm{TN}$ 含量 & $\mathrm{TP}$ 含量 \\
\hline 污染层与过渡层 & 0.003 & 0.564 & 0.624 & 0.063 & 0.095 & 0.001 & 0.051 \\
过渡层与健康层 & 0.013 & 0.280 & 0.131 & 0.424 & 0.417 & 0.115 & 0.983 \\
\hline
\end{tabular}

污染层含水率最高, 其次为氧化层, 其含水率比污染层降低 $7.20 \%$, 过渡层、健康层含水率依次降低; 各 层 $\mathrm{d}(0.1)$ 变幅较小, 最大差值为 $0.22 \mu \mathrm{m}$; 氧化层的 $\mathrm{d}(0.5)$ 比污染层升高 $9.57 \%$, 污染层 $\mathrm{d}(0.5)$ 最小, 过渡 层和健康层的 $\mathrm{d}(0.5)$ 有略上升的趋势, 但变幅较小; 氧化层的 $\mathrm{d}(0.9)$ 与污染层相比差别较大, 降低 $54.04 \%$, 过渡层与健康层的 $\mathrm{d}(0.9)$ 分别比氧化层降低 $13.92 \%$ 和 $8.35 \%$; 各层 TOC 含量及 TN 含量变化趋势相似, 与 污染层相比, 氧化层 TOC 含量及 TN 含量分别降低 $17.89 \%$ 和 $7.00 \%$, 污染层 TOC 和 TN 含量最高, 过渡层及 健康层比污染层明显降低; 各层 TP 含量随深度增加依次降低, 氧化层 TP 含量与污染层相比升高 $18.27 \%$, 过渡层、健康层 TP 含量与污染层相比明显降低( 图 8). 

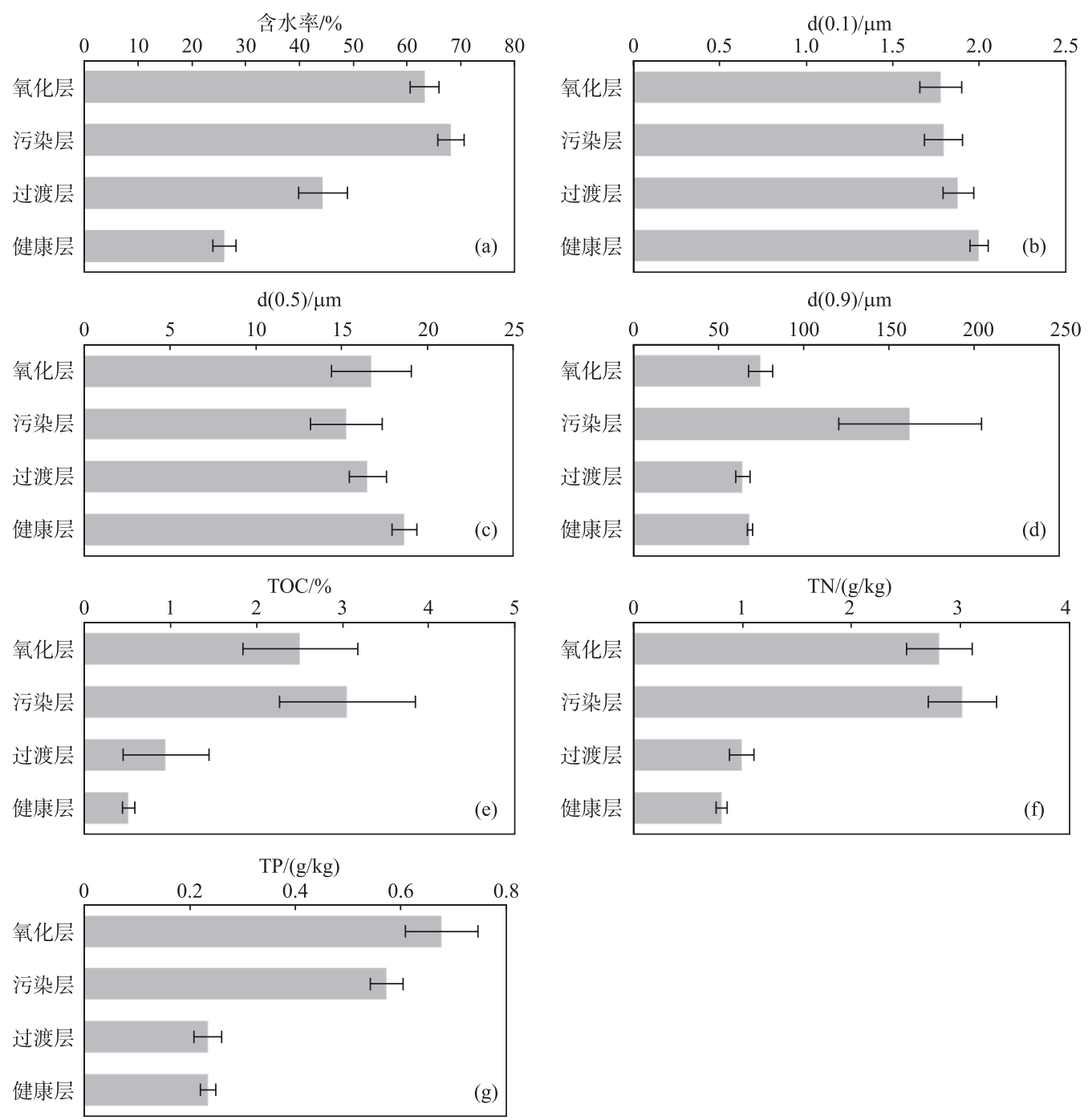

图 8 盐龙湖湿地底泥分层理化性质对比

Fig. 8 Contrast of physicochemical property of Yanlong Lake Wetland sediments

\section{3 讨论}

\section{1 长期运行表面流人工湿地底泥污染特性}

本文研究发现,湿地底泥中污染物的分布在垂向分布上总体呈现明显分层规律, 可分为氧化层、污染 层、污染过渡层、健康层. 底泥在表面形成了一层 TP 含量及 $\mathrm{Eh}$ 高, 有机质、总氮含量、亚铁含量较低的氧化 层, 氧化层下层为有机质、TN 含量、亚铁含量达到峰值的污染层, 污染层以下底泥污染物含量迅速降低并逐 渐恢复原土状态. 人工湿地在长期运行下产生上述分层结果的原因如下:

氧化层由于氧气补给较为充足, Eh 较污染层高, 所以还原性致黑物质及有机质含量减少, 沉降或被氧 化的无定形态的氧化物和水合氢氧化物等无机颗粒物增多,比如 $\mathrm{Fe} 、 \mathrm{Al} 、 \mathrm{Mn}$ 和 $\mathrm{Ca}$ 等氧化物胶体以及带着基 基团的黏土矿物等 ${ }^{[10-11]}$. 该无机颗粒物质粒径较小且具有较强的致密性, 提高了氧化层的致密程度, 降低了 氧化层孔隙率, 所以氧化层含水率及粒径均偏小. 氧化层较高的致密程度阻碍了上覆水溶解氧底泥深层扩 
散, 加剧了氧化层与污染层氧化还原环境的分异. 氧化层呈现好氧状态, 好氧菌活动频繁, 氧化分解作用较 强, 而污染层呈现厌氧状态, 还原性物质堆积, 有机质分解速度较慢. 底泥中有机质含量和总氮含量具有较 好的相关性, 说明湿地底泥中的氮主要来自有机污染物的迁移和累积, 即植物的生长代谢, 氮元素主要以有 机氮的形式存在于底泥中 ${ }^{[12-13]}$. 氧化层由于好氧分解作用较强, 部分有机质被分解, 有机质含量及有机氮含 量均有所下降, 无机化后的氮以水溶离子的方式通过溶解于间隙水而释放到上覆水中 ${ }^{[14-15]}$. 所以, 氧化层有 机质含量及总氮含量均偏低. 上述无机颗粒物质具有较强的离子吸附能力, 离子态磷与氧化层中多种无机 颗粒物质发生物理甚至化学吸附 ${ }^{[16-17]}$, 重新形成某种形态的磷 ${ }^{[18-20]}$, 所以氧化层总磷含量比污染层偏高.

污染层为植物根系新陈代谢的主要区域, 常年运行的表面流人工湿地污染层累积了大量烂根有机质, 由于缺乏氧气补给, 该层有机质分解以厌氧分解为主, 易产生硫化氢 $\left(\mathrm{H}_{2} \mathrm{~S}\right)$ 、氨氮 $\left(\mathrm{NH}_{3}\right)$ 等致臭物质以及腐 殖质类有机物和硫化亚铁 $(\mathrm{FeS})$ 等致黑物质 ${ }^{[21-22]}$. 腐殖质与 $\mathrm{Fe} 、 \mathrm{Al}$ 等重金属形成具有一定团粒结构和黏结 性质的水溶络合物胶体 ${ }^{[23]}$, 形成污染层多孔、疏松、易流动的状态. 所以, 污染层含水率、粒径大小、有机质 含量、总氮含量均达到峰值.

污染过渡层是污染层和健康层的过渡, 由于其逐渐远离主根区, 有机质累积强度不断减弱, 所以含水 率、有机质含量、TN 含量、TP 含量在过渡层随深度增加不断降低. 健康层距离主根区较远, 基本无植物根系 有机质累积污染,含水率及有机质含量、总氮含量、总磷含量进一步降低,土质与原土接近.

结合以往关于底泥污染累积方面的研究成果从 底泥污染累积平均水平来看, 盐龙湖湿地底泥污染 累积时间长达 6 年, 底泥中有机质、总氮的累积水平 跟乌克兰运行 8 年人工湿地相当 ${ }^{[24]}$, 均明显高于一 般河湖和自然湿地 ${ }^{[25-27]}$ (表 7). 这是由于湿地植物 根系新陈代谢和茎叶残体腐败成为湿地底泥中污染 物累积的重要来源. 在植物生长阶段, 底泥中植物新 根生成从而旧根腐烂堆积成为湿地底泥污染物累积 的主要来源. 在植物枯萎阶段, 茎叶枯萎后容易倒 伏, 尤其是艾草冬季呈现大面积倒伏状态, 倒伏后的 茎叶残体附着于底泥表面, 不断累积, 成为底泥污染 物的又一重要来源.

表 7 盐龙湖湿地底泥与其他底泥污染物 平均水平对比 ${ }^{[24-27]}$

Tab.7 Contract of pollutant concentrations in Yanlong Lake Wetland sediments and other sediments

\begin{tabular}{cccc}
\hline \multirow{2}{*}{ 湿地 } & \multicolumn{3}{c}{ 底泥污染平均水平 $/ \%$} \\
\cline { 2 - 4 } & 总氮 & 总磷 & 总有机碳 \\
\hline 盐龙湖湿地 & 0.302 & 0.057 & 3.057 \\
乌克兰运行 8 年人工湿地 & 0.41 & 0.15 & 2.19 \\
巢湖 & 0.108 & 0.053 & 1.111 \\
罗时江河口湿地 & 0.231 & 0.133 & 1.474 \\
天津芦苇沼泽湿地 & 0.160 & 0.050 & 1.498 \\
\hline
\end{tabular}

\section{2 长期运行表面流人工湿地氧化层形成机理}

整体来看, 同一净化单元从进水口至出水口, 氧化层厚度有下降趋势, 含水率、粒径大小有升高趋势, 有 机质含量、总氮含量有上升趋势, 总磷含量变化趋势不明显. 不同运行水深净化单元相比, 随水深的增加, 氧 化层厚度有增加趋势, 氧化层含水率有降低趋势, 氧化层粒径大小、有机质含量、总氮含量、总磷含量均有下 降趋势. 下面结合湿地进出水水质数据、水动力数据、植物根系长度数据详细分析以上指标变化趋势原因, 并深刻探讨氧化层形成的机理.

氧化层的形成受上覆水水质条件、水动力条件、植物新陈代谢等多种因素的影响. 上覆水溶解氧水平直 接决定了氧化层的氧化还原条件, 密切影响了氧化层中好氧微生物的活性, 决定了氧化层的有机质含量和 致密程度. 上覆水中一定量的悬浮物和较好的水动力沉降条件可使悬浮物发生沉降, 使氧化层明显变厚, 增 加氧化层的垂向尺度. 植物根系泌氧效应可直接改善氧化层的氧化还原条件, 加快氧化层的形成, 同时也一 定程度上增加氧化层厚度 ${ }^{[4-5]}$.

盐龙湖湿地表面流速变化范围为 $0.1471 \sim 0.441 \mathrm{~m} / \mathrm{s}$, 平均流速为 $0.265 \mathrm{~m} / \mathrm{s}$. 每个净化单元平均面积为 2.29 万 $\mathrm{m}^{2}$, 平均进水量为 1.67 万 $\mathrm{m}^{3} / \mathrm{d}$, 水力停留时间为 $6 \sim 8 \mathrm{~h}$. 根据理论计算结果, 盐龙湖湿地在以上正常 水动力条件下不会造成湿地氧化层起悬, 这是氧化层产生的基础条件. 氧化层是在氧化和沉降协同作用下 形成的,所以氧化作用和沉降作用是影响氧化层理化性质的两个关键因素. 沉降作用主要受上覆水悬浮物 含量、水动力沉降条件 (水深、流速等) 的影响, 氧化作用主要受上覆水溶解氧水平和植物泌氧水平的影响. 在无人为干扰的一般情况下, 沉降作用对氧化层厚度起着决定作用, 上覆水悬浮物含量越高、沉降条件越 
好, 氧化层越厚. 氧化作用对氧化层致密程度和有机质含量起决定作用, 上覆水溶解氧水平越高、植物泌氧 效果越好, 氧化层产生的铁、锰等氧化物及无机颗粒物质含量越高, 因而氧化层致密程度越高, 有机质含量 占比相对降低.

根据盐龙湖湿地进出水水质监测结果的多年平均情况, 出水口悬浮物浓度比进水口降低 $36.03 \%$, 溶解 氧浓度降低 $35.79 \%$, 所以盐龙湖湿地同一净化单元由进水口至出水口方向, 上覆水中溶解氧含量及悬浮物 含量均不断减少. 由进水口至出水口, 氧化层的沉降作用和氧化作用均不断削弱, 因此随水流方向氧化层变 薄、致密程度变低、TOC 及 $\mathrm{TN}$ 含量均减少, 但由于植物条件及上覆水条件的不确定性, 部分数据不符合该规 律. 氧化层中磷元素赋存形态以无机磷为主, 与氧化层无机物团粒结构、金属氧化物含量等多种因素有关, 吸附状态随水流无稳定变化规律,所以氧化层 TP 含量变化无稳定规律.

不同运行水深情况下, 水动力沉降条件发生变化, 水深越深沉降条件越好. 当前运行水深条件下没有产 生上覆水溶解氧跃层, 所以不同运行水深净化单元的相同位置上覆水溶解氧对氧化层的氧化条件相同. 本 研究结果结合以往研究成果 ${ }^{[4-5]}$ 表明, 植物泌氧作用对氧化层的形成具有较为重要的作用. 徐宽等 ${ }^{[4]}$ 研究苦 草对城市缓流河道黑臭底泥理化性质的影响发现, 种植苦草的实验组表层底泥氧化层形成时间早且随时间 推移逐渐增厚, 厚度为 $3 \sim 11 \mathrm{~mm}$, 无苦草实验组氧化层形成时间晚且厚度仅为 $1 \mathrm{~mm}^{[4]}$. 说明植物根系泌氧

表 8 各采样点植物根系长度

Tab.8 Length of plants' roots of each sampling site

\begin{tabular}{ccccc}
\hline \multirow{2}{*}{ 分区 } & \multirow{2}{*}{ 水深 $/ \mathrm{m}$} & \multicolumn{3}{c}{ 根系长度/ $\mathrm{cm}$} \\
\cline { 3 - 5 } & & 进水口 & 中间 & 出水口 \\
\hline A 区 & 0.3 & 44 & 13 & 25 \\
B 区 & 0.4 & 21 & 26 & 21 \\
C 区 & 0.5 & 27 & 42 & 36 \\
\hline
\end{tabular}

作用对氧化层性质具有重要影响, 同时植物泌氧作用也 加快了氧化层的形成且增加了其厚度. 因此, 在盐龙湖 湿地中,由于植物相对密集, 植物根系泌氧作用明显, 所 以不同区域氧化层性质也不同. 从表 8 可以看出, C 区植 物根系最长, 植物泌氧作用要好于 A 区, B 区根系最短, 植物泌氧作用最差. 因此, C 区氧化层厚度大于 A 区, 氧 化层有机碳、有机氮含量小于 A 区, 氧化层致密程度相 对 A 区有所增加. B 区植物根系泌氧条件最差, 所以氧 化层有机质含量最高.

\section{3 氧化层的产生可能对水一土界面物质迁移转化规律产生的影响}

自然条件下的土壤经过物理和化学作用表层土壤团聚体会破碎形成致密层, 称为结皮现象 ${ }^{[28]}$, 该结皮 现象的产生一定程度上抑制了自然条件对土壤更深层的侵蚀 ${ }^{[29]}$. 从本文以上论述可以发现氧化层含水率 较低、致密程度较高, 属于湿地中底泥的“结皮现象”. 含水率含量及粒径分布与底泥致密程度紧密相关, 含 水率越低、粒径越小, 底泥的致密程度越高, 越不利于底泥的再悬浮, 从而抑制底泥营养物质向上覆水中迁 移扩散 ${ }^{[12]}$. 有学者研究表明, 底泥悬浮对污染物释放有明显促进作用 ${ }^{[30]}$. 因此, 氧化层的形成一方面阻碍了 上覆水溶解氧向底泥深层扩散, 另一方面使底泥不容易产生悬浮, 一定程度上阻碍了深层底泥污染物向上 覆水中扩散, 同时由于氧化层中无机物的增加增强了对上覆水中磷的吸附.

\section{4 结论与展望}

1) 长期运行的表面流人工湿地底泥表层会形成一层厚度约为 $1 \mathrm{~cm}$ 、棕黄色、无明显臭味、可塑状的氧化 层. 作为湿地水一土界面之间污染物迁移转化的边界层, 氧化层易成为上覆水与污染层的稳定隔层, 不利于 底泥污染向上覆水扩散释放, 影响污染物在水一土界面的迁移转化规律并阻止上覆水溶解氧向底泥深层扩 散,造成氧化层上下两侧氧化还原环境、污染物含量、微生物群落之间的差异.

2) 与底泥污染层相比, 氧化层具有颜色变浅、臭味减弱、致密程度增加、亚铁含量降低、Eh 升高、有机质 含量减小、无机磷含量增多等特征. 与污染层相比, 氧化层色味变淡、流动性减弱, 含水率、 $\mathrm{d}(0.9)$ 、亚铁、TOC 和 TN 含量分别降低 7.20\%、54.04\%、54.59\%、17.89\% 和 7.00\%, Eh 和 TP 含量分别升高 $150.41 \%$ 和 $18.17 \%$.

3) 与湖泊类似, 长期运行的表面流人工湿地底泥会产生由上到下分别为氧化层、污染层、过渡层、健康 层的明显分层现象, 且在 70\% $85 \%$ 置信区间下氧化层与污染层、污染层与过渡层、过渡层与健康层之间绝 大多数理化性质存在显著差异.

4) 湿地氧化层性质受上覆水水质、水动力条件、植物生长状况的共同影响. 氧化层性质呈现由进水口至 
出水口厚度减小、含水率及粒径增大、有机质及总氮含量增大的趋势, 同时呈现随运行水深的增加厚度增 加、含水率及粒径减小、有机质及总氮含量减小的趋势. 这是由于氧化作用对氧化层致密程度、有机质含量 起决定作用, 沉降作用对氧化层厚度起着决定作用. 一般情况下, 上覆水悬浮物越多、水动力沉降条件越好 则氧化层越厚; 植物泌氧水平越高、上覆水溶解氧水平越高则氧化层越致密、有机质含量占比越低.

综上所述, 长期运行的人工湿地由于上覆水沉降、溶解氧及植物根系泌氧协同氧化易形成薄且致密的 氧化层, 氧化层对湿地底泥污染源汇转换关系存在较为重要的意义, 其对水一土界面污染物迁移转化规律、 微生物群落结构、产生何种重要影响等方面还需进一步加强微观层次的研究. 另外, 氧化层的形成过程和形 成周期以及如何利用氧化层的作用来减少湿地底泥内源污染均需要更深层次的研究.

致谢: 盐城市盐龙湖饮用水源管理处的杜观超主任、高旭科长、李峰东助工, 盐城市节约用水办公室的陈红 卫主任, 河海大学的张海阔、朱伊梦、秦文凯同学在数据获取过程中给予了很大的支持和帮助, 在此表示衰 心的感谢!

\section{5 参考文献}

[ 1 ] Zhou XW, Shen MX, Jin MJ et al. Purification effect on aquaculture wastewater by multi-series surface flow constructed wetland. Wetland Science, 2017, 15(6): 774-780. [周新伟, 沈明星, 金梅娟等. 多级串联表面流人工湿地对河蟹养 殖尾水的净化效果研究. 湿地科学, 2017, 15(6): 774-780.]

[ 2 ] Wang WM, Wei JX, Dai TH et al. Discussion of key technologies for operation management of the constructed wetland. Environmental Protection Science, 2014, 40(3) : 24-28. [王文明, 危建新, 戴铁华等. 人工湿地运行管理关键技术探 讨. 环境保护科学, $2014,40(3): 24-28$.]

[ 3 ] Jiang X, Wang WW, Wang SH et al. Calculation of environmental dredging depth of heavy metal polluted sediments in Zhushan Bay of Taihu Lake. Environmental Science, 2012, 33(4): 1189-1197. [姜霞, 王雯雯, 王书航等. 竺山湾重金 属污染底泥环保疏浚深度的推算. 环境科学, 2012, 33(4): 1189-1197.]

[ 4 ] Xu K, Liu B, Wang GX et al. Influence of Vallisneria spiralis on the physicochemical properties of black-odor sediment in urban sluggish river. Environmental Science, 2013, 34(7): 2642-2649. [许宽, 刘波, 王国祥等. 苦草( Vallisneria spiralis) 对城市缓流河道黑臭底泥理化性质的影响. 环境科学, 2013, 34(7): 2642-2649.]

[ 5 ] Ou Y. Effects of root oxygen secretion in typical wetland plants on rhizosphere REDOX environment [Dissertation]. Nanjing: Nanjing Normal University, 2015. [欧媛. 典型湿地植物根系泌氧对根际氧化还原环境的影响 [学位论文]. 南 京: 南京师范大学, 2015.]

[ 6 ] Gu XZ, Chen KN, Zhang L et al. Preliminary evidence of nutrients release from sediment in response to oxygen across benthic oxidation layer by a long-term field trial. Environmental Pollution, 2016, 219: 656-662. DOI: 10.1016/j. envpol. 2016.06.044.

[ 7 ] Li YP. Study on the influence factors of transparency by experiment and numerical model in Lake Taihu [Dissertation]. Nanjing: Hohai University, 2006. [李一平. 太湖水体透明度影响因子实验及模型研究 [学位论文]. 南京: 河海大 学, 2006.]

[ 8 ] Xian P, Tang HF, Feng XJ et al. A method for in-situ control of contaminated pond sediment: CN106277683A, 2017. [冼萍, 唐海芳, 冯晓娟等.一种受污染湖塘底泥原位控制的方法: CN106277683A, 2017.]

[ 9 ] Wang Y, Ding S, Wang D et al. Static layer: a key to immobilization of phosphorus in sediments amended with lanthanum modified bentonite (Phoslock (C). Chemical Engineering Journal, 2017, 325: 49-58. DOI: 10.1016/j.cej.2017.05.039.

[10] Li JC, Wang PY, Tan YY et al. Experimental research on the layering characteristics of contaminated bottom sediment and its pore water. Environmental Pollution \& Control, 2004, 26(5): 323-325, 315. [李剑超, 王培英, 谭远友等. 污染底 泥及其间隙水分层特性的模拟实验研究. 环境污染与防治, 2004, 26(5) : 323-325, 315.]

[11] Liu T, Wang H, Zhang Z et al. Application of synthetic iron-oxide coated zeolite for the pollution control of river sediments. Chemosphere, 2017, 160: 168. DOI: 10.1016/j.chemosphere.2017.04.023.

[12] Yuan JL, Li M, Yang YJ et al. Analysis of characterization, nutrient content and pollution status of sediment in Yankou Reservoir, Yiwu City. Journal of Zhejiang Ocean University, 2015, 34(3) : 255-262. [ 原居林, 李明, 杨元杰等. 义乌 市岩口水库底泥特征、营养盐含量及污染现状分析.浙江海洋学院学报: 自然科学版, 2015, 34(3): 255-262.]

[13] Ding JH, Wang CH, Zhou XC et al. On the characteristics of nitrogen and phosphorus in the sediments of Jinyang Lake. 
Journal of Safety \& Environment, 2008, (3) : 14-17. [丁建华, 王翠红, 周新春等. 晋阳湖底泥中氮磷特征的初步研 究. 安全与环境学报, 2008, (3) : 14-17.]

[14] Xia X, Zhang S, Li S et al. The cycle of nitrogen in river systems: sources, transformation, and flux. Environmental Science Processes \& Impacts, 2018, 20(6) : 863-891. DOI: 10.1039/c8em00042e.

[15] Wen SL, Gong WQ, Wu T et al. Distribution characteristics and fluxes of nitrogen and phosphorus at the sediment-water interface of Yuqiao Reservoir. Environmental Science, 2018, 39(5) : 2154-2164. DOI: 10.13227/j.hjkx.201709081.

[16] Li Y, Wang C. Experimental study on phosphate release from sediments of an urban shallow lake. Environmental Science \& Technology, 2003, (1) : 26-28, 64-65. [李勇, 王超. 城市浅水型湖泊底泥磷释放特性实验研究. 环境科学与技术, $2003,(1): 26-28,64-65$.

[17] Zhu YQ. Study on the releasing of nutrient from sediment of Dianshan Lake and its influencing factors. Environmental Pollution \& Control, 2014, 36(5) : 70-77. [朱永青. 淀山湖底泥氮磷营养盐释放及其影响因素研究. 环境污染与防 治, 2014, 36(5): 70-77.]

[18] Zhang W, Jin X, Zhu X et al. Do $\mathrm{NH}_{3}$ and chemical oxygen demand induce continuous release of phosphorus from sediment in heavily polluted rivers? Ecological Engineering, 2017, 102: 24-30.

[19] Wang T, Liu J, Xu S et al. Spatial distribution, adsorption/release characteristics, and environment influence of phosphorus on sediment in reservoir. Water, 2017, 9(9) : 724. DOI: 10.3390/w9090724.

[20] Lu JP, Ma TL, Liu T et al. Study on sediment phosphorus release mechanism of the environmental impact in Dahekou Reservoir. Environmental Science \& Technology, 2017, 40(7) : 72-78.

[21] Wang LJ, Wu SL. Pollution Characteristics and contamination assessment of sediment from black-dor Rivers in Nanjing City. Science Technology and Engineering, 2018, 18(3): 117-122. [王莉君, 吴思麟. 南京黑臭河道底泥污染特征及评 价. 科学技术与工程, 2018, 18(3): 117-122.]

[22] Cai P, Wu YC, Liu X et al. The contribution of sediment and algal to the formation of black bloom and their potential to supply the black substance in waters in Lake Taihu. J Lake Sci, 2015, 27(4) : 575-582. DOI: 10.18307/2015.0403. [蔡 萍, 吴雨琛, 刘新等. 底泥和藻体对太湖湖泛的诱发及水体致黑物的供应潜力. 湖泊科学, 2015, 27 (4): 575-582.]

[23] Yi CQ. Discussion on basic idea of controlling urban black smelly river water. Water Resources Development \& Management, 2017，(4)：14-16. [易春权. 城市黑臭河道水体治理基本思路的探讨. 水资源开发与管理，2017，(4)：14-16.]

[24] Vergeles Y, Butenko N, Ishchenko A et al. Formation and properties of sediments in constructed wetlands for treatment of domestic wastewater. Urban Water Journal, 2016, 13(3) : 293-301. DOI: 10.1080/1573062X.2014.993178.

[25] Wang YH, Qian SM, Xu NN et al. Characteristics of distribution of pollutants and evaluation in sediment in the east area of Chaohu Lake. Research of Environmental Sciences, 2004, 17(6): 22-26. [王永华, 钱少猛, 徐南妮等. 巢湖东区底 泥污染物分布特征及评价. 环境科学研究, 2004, 17(6) : 22-26.]

[26] Wang SJ, Liu YG, Zhang C et al. Distribution and pollution risk assessment of nitrogen, phosphorus and organic matter in inlet rivers of Erhai Basin. J Lake Sci, 2017, 29(1) : 69-77. DOI: 10.18307/2017.0108. [王书锦, 刘云根, 张超等. 洱海流域人湖河口湿地沉积物氮、磷、有机质分布及污染风险评价. 湖泊科学, 2017, 29(1): 69-77.]

[27] Liu D, Chen Q, Wang YD et al. Carbon, nitrogen and phosphorus in sediments of Phragmites australis marshes in Tianjin City and its ecological stoichiometry characteristics. Wetland Science, 2016, 14(6): 908-915. [刘丹, 陈清, 王义东等. 天津市芦苇沼泽底泥中的碳、氮和磷分布及其生态化学计量学特征. 湿地科学, 2016, 14(6) : 908-915.]

[28] Shi W, Wang XP, Zhang YF et al. Response of soil moisture in shallow depth to stochastic rainfall and biological crust in revegetated sand dunes in the Tengger Desert. Journal of Desert Research, 2018, 38(3): 600-609. [石薇, 王新平, 张亚 峰. 腾格里沙漠人工固沙植被区浅层土壤水分对降水和生物结皮的响应. 中国沙漠, 2018, 38(3) : 600-609.]

[29] Gao LQ. Effects and the mechanisms of biological soil crusts on water erosion prevention on the loess plateau [ Dissertation]. Yangling: Research Centre of Soil and Water Conservation \& Eco-environment, 2017. [高丽倩. 黄土高原生物结 皮土壤抗水蚀机理研究 [学位论文]. 杨凌: 中国科学院教育部水土保持与生态环境研究中心, 2017.]

[30] Hu KM, Wang S, Pang Y. Suspension-sedimentation of sediment and release amount of internal load in Lake Taihu. J Lake $S c i, 2014,26$ (2) : 191-199. DOI: 10.18307/2014.0204. [胡开明, 王水, 逢勇. 太湖不同湖区底泥悬浮沉降规律研 究及内源释放量估算. 湖泊科学, 2014, 26(2) : 191-199.] 